\title{
Prevalence and determinants of nutritional anemia in an urban area among unmarried adolescent girls: A community-based cross-sectional study
}

Vani Srinivas, Ranjit Mankeshwar

Department of Community Medicine, Grant Medical College, JJ Hospital Campus, Byculla, Mumbai, Maharashtra, India

Address for the Correspondence:

Dr. Vani Srinivas, 409, Mahaveer Willow Apartment, Kengeri Satellite Town, Bangalore, 560060 , India.

E-mail: drvanisri@yahoo.co.in

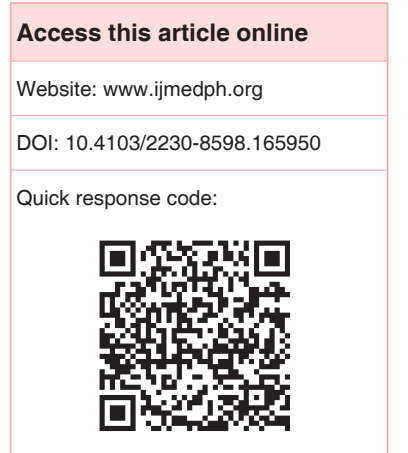

Introduction: Nutrition status prior to pregnancy is of vital importance. Inadequate iron stores bef ore conception is a major cause of iron deficiency. The primary objective of this research was to estimate the prevalence of anaemia and the secondary objective was to assess various epidemiological factors associated with anaemia. Methods: A community based, cross - sectional study was carried among 207 unmarried adolescent girls between 10 to 19 years, residing in urban field practice area of tertiary care hospital in Mumbai for one year. All study participants social demographic profile, diet history was collected. Findings of clinical examination, height and weight was recorded. Blood and stools samples were collected after obtaining verbal consent from their parents. Univariate and binary logistic regression analysis was done using SPSS 11.5 version. Results: The overall prevalence of anaemia was $78.3 \%$. Prevalence of mild, moderate and severe anaemia was $64.2 \%, 36.2 \%$ and $0.6 \%$ respectively. Study participants with $\mathrm{BMI}<18.5 \mathrm{Kg} / \mathrm{M}^{2}$ had significantly higher prevalence of anaemia. $88.9 \%$ had no knowledge regarding anaemia. In logistic regression analysis body mass index, per capita income and intestinal parasites in stool were the variables independently associated with anaemia. Conclusions: The high prevalence of anaemia among adolescent girls indicates need for additional nutritional support, iron folic acid supplementation including prevention and control of worm infestation in urban communities. It would be desirable that action for improvement is initiated right at the adolescent stage, thereby ensuring adequate body stores of iron even before they marry and become pregnant.

Key words: Epidemiological determinant, India, iron deficiency

\section{INTRODUCTION}

Adolescents aged 10-19 years constitute about $21 \%$ of India's population which in absolute numbers translates to 253 million. ${ }^{[1]}$ However, a considerable number of adolescents face challenges to their healthy development due to a variety of factors, including structural poverty, social discrimination, negative social norms, and early marriage and child-bearing, especially in the marginalized and under-served sections of the population. ${ }^{[2]}$

Adolescent girls are particularly at higher risk of malnutrition because of gender discrimination in distribution of, and access to, food within family. ${ }^{[3]}$ In adolescent girls, nutrition status prior to pregnancy is important. Inadequate iron stores before conception is a major cause of iron deficiency anemia during pregnancy. ${ }^{[3]}$

This is an open access article distributed under the terms of the Creative Commons AttributionNonCommercial-ShareAlike 3.0 License, which allows others to remix, tweak, and build upon the work non-commercially, as long as the author is credited and the new creations are licensed under the identical terms.

For reprints contact: reprints@medknow.com

How to cite this article: Srinivas V, Mankeshwar R. Prevalence and determinants of nutritional anemia in an urban area among unmarried adolescent girls: A community-based cross-sectional study. Int J Med Public Health 2015;5:283-8. 
As estimated by United Nations, iron deficiency is the most common nutritional deficiency worldwide, affecting 1 billion people, particularly women of the reproductive age and young children. ${ }^{[4]}$

Investments in adolescent girls will have an immediate, direct, and positive impact on India's health goals and on the achievement of the Millennium Development Goals, especially Goal 1: Eradicate Extreme Hunger and Poverty, Goal 2: Achieve Universal Primary Education, Goal 3: Promote Gender Equality and Empower Women, Goal 4: Reduce Child Mortality, Goal 5: Improve Maternal Health, and Goal 6: Combat HIV/AIDS, Malaria, and other diseases, at the same time, it will enhance economic productivity, effective social functioning, and overall population development. The increasing share of adolescents and youth in India's population can translate into a demographic dividend only if policies and programs focus on the health and well-being of this large, yet very vulnerable population. ${ }^{[5,6]}$

There are many studies on anemia in pregnancy and in children $<5$ years old; however, there is inadequate attention to the presence of anemia in adolescent girls, who are future mothers. This study highlights the problem of health, nutritional anemia, and education status of adolescent girls in urban area. The primary objective of this research was to estimate the prevalence of anemia, and the secondary objective was to assess various epidemiological factors associated with anemia.

\section{MATERIALS AND METHODS}

\section{Study area}

The present study is a community-based cross-sectional study. The study participants were daughters of government class IV employees residing in government housing colony that was the part of an urban field practicing area of tertiary care hospital in Mumbai.

\section{Study duration}

The study was carried out from January to December 2004.

\section{Inclusion criteria}

Unmarried, nonpregnant, and nonlactating girls in the age group of 10-19 years residing in government colony were included in the study. The questionnaire was administered only if parents gave oral consent for examination of blood and stool samples. If there were more than one adolescent girl in the same household, only the eldest adolescent girl of the family was enrolled in the study.

\section{Sample size}

The World Health Organization non — serial publication "the sample size determination" 1993 was relied upon. A table on sample size calculation at page no. 27 was the basis of sample size determination. ${ }^{[7]}$ The formula used was sample size $(n)=\tau_{1-\alpha / 2}^{2}(1-P) / \varepsilon^{2}$, the quantity $z$ represents the number of standard errors away from the mean, $\tau_{1-\alpha / 2}^{2}$ is functions of confidence level (95\%), $P$ is anticipated population prevalence that was considered as $64 \%, \varepsilon$ a relative precision of 0.1 $(10 \%)$, and the sample size worked out to be $207 . .^{[8]}$

\section{Sampling}

A two-stage sampling method was followed. Initially, a baseline study was done in all 13 buildings, of class IV employees. The total population of 13 buildings was 6880, of which 540 were the adolescent girls. In the second stage by simple random sampling method, 207 girls were selected using random number table.

\section{Data and sample collection}

The questionnaire consists of sociodemographic data, menstrual history, dietary intake (was assessed by 24 hours recall method), dietary nutrient intake, and knowledge regarding iron-rich food and clinical examination of the selected participants. Hemoglobin was assessed by Sahli's method. Trained pathologists examined peripheral blood smear on the same day. Stool examination for the assessment of ova and cyst of each study participant was done at the health centers by qualified and trained laboratory technicians. Repeated reminders were given to the girls to submit the stool samples for examination.

\section{Statistical analysis}

For the purpose of statistical analysis, those with hemoglobin $<12$ $\mathrm{g} / \mathrm{dl}$ were categorized as having anemia and those with hemoglobin more than or equal to $12 \mathrm{~g} / \mathrm{dl}$ were categorized as not having anemia.

Data were analyzed using the Statistical Package for Social Sciences (SPSS) version 11.5 software (SPSS Inc. Chicago, USA). For assessing difference between proportions in qualitative data, Pearson's Chisquare test was used as a test of significance. $P<0.05$ is considered as statistically significant. When the expected value in a cell was $<5$ in a $2 \times 2$ table, Fisher's exact test was used as a test of significance, and when the expected value in a cell was $<5$ in other tables, likelihood ratio test was used a test of significance.

Binary logistic regression was done using the dependent variable in the present study that was anemia status. Variables that had $P<0.1$ in a univariate analysis were considered for entry into the regression model.

Institutional Review Board, of Grant Medical College, Mumbai, approved the study. Oral consent was taken from parents to collect information, blood, and stool samples.

\section{RESULTS}

A total of 207 study participants were enrolled in the study.

\section{Sociodemographic profile}

Table 1 shows the sociodemographic profile of the study participants. Of 207 study participants, 47 (22.7\%) belonged to the $10-12$ years age group, 81 (39.1\%) were in 13-15 years age group, and $79(38.2 \%)$ were in the 16-18 years age group. Caste-wise distribution of study participants showed that 104 (50\%) belonged to open category, 82 $(39.2 \%)$ belonged to scheduled caste or schedule tribe community, and $21(10.2 \%)$ were from other backward caste and other castes. The majority of the study participants' fathers $(100 ; 48.3 \%)$ had completed 
secondary education. The majority $(191 ; 92.3 \%)$ of study participants' mothers were housewives, and 148 (71.5\%) belonged to families with 4 or less members, and $148(80.7 \%)$ belonged to a nuclear family.

\section{Prevalence of Anemia}

Table 2 shows prevalence, grade, and knowledge of anemia among study participants. The overall prevalence of anemia was $78.3 \%$.

\begin{tabular}{lc}
\multicolumn{2}{l}{ Table 1: Sociodemographic profile of the study } \\
participants \\
\hline Characteristics & $\boldsymbol{n}(\%)$ \\
\hline Age groups (years) & \\
$10-12$ & $47(22.7)$ \\
$13-15$ & $81(39.1)$ \\
$16-18$ & $79(38.2)$ \\
Caste distribution & \\
Open category & $104(50.22)$ \\
Scheduled caste/schedule tribe & $82(39.2)$ \\
OBC and others & $21(10.2)$ \\
Father's education & \\
Up to primary & $4(1.8)$ \\
Primary completed & $91(44)$ \\
Secondary completed & $100(48.3)$ \\
Higher secondary and above & $12(5.7)$ \\
Education status of study participants & \\
Up to primary & $146(70.5)$ \\
Secondary & $44(21.3)$ \\
Higher secondary & $17(8.2)$ \\
Mothers' occupation & \\
Housewives & $191(92.3)$ \\
Employed & $16(7.7)$ \\
Type of family & \\
Nuclear & $167(80.7)$ \\
Joint and extant & $40(19.3)$ \\
Total family members & \\
Mp to 4 members & $148(71.5)$ \\
\hline
\end{tabular}

$n=$ Total number of participants

\begin{tabular}{lc} 
Table 2: Prevalence, grade of anemia, and \\
knowledge of anemia among study participants \\
\hline \multicolumn{1}{l}{ Characteristics } \\
\hline Prevalence of anemia $(\mathrm{gm} / \mathrm{dl})$ \\
Present (hemoglobin $<12)$ & $162(78.3)$ \\
Absent (hemoglobin $>12)$ & $45(21.7)$ \\
Grades of anemia $(\mathrm{gm} / \mathrm{dl})$ & \\
Mild $(10-11.9)$ & $104(64.2)$ \\
Moderate $(7-9.9)$ & $59(36.2)$ \\
Severe $(<7)$ & $1(1)$ \\
Prevalence of anemia in different age groups (years) & \\
$10-12$ & $42(25.9)$ \\
$13-15$ & $59(36.4)$ \\
$16-19$ & $61(37.6)$ \\
Knowledge about anemia & \\
Yes & $23(11.1)$ \\
No & $184(88.9)$ \\
\hline
\end{tabular}

The prevalence of mild, moderate, and severe anemia was $64.2 \%$, $36.2 \%$ and $1 \%$, respectively. Prevalence of anemia in the $10-12$ years age group study participants was $25.9 \%, 13-15$ years age group was $36.4 \%$, and $16-18$ age group was $37.6 \%$. Of the 207 participants, $126(60.8 \%)$ had hypochromic microcytic erythrocytes, indicating iron deficiency anemia, 25 (12.3\%) participants had dimorphic anemia, that is, hypochromic microcytic with macrocytic erythrocytes, indicating iron and folic acid deficiency state. Around $9(4.3 \%)$ participants had macrocytic anemia, indicating folic acid and vitamin B12 deficiency. 29 (14\%) had early iron deficiency indicated by hypochromic normocytic erythrocytes. Only 18 $(8.6 \%)$ subjects had normochromic normocytic erythrocytes (data not shown). Majority of participants (88.9\%) had no knowledge regarding anemia.

\section{Univariate analysis}

Table 3 shows univariate analysis of factors associated with anemia. Among socio-demographic variables, the age group of study participants and mothers education were the factors not associated with anemia. However, the family size of more than 4, mothers' occupation as housewife, and per capita income of less than Rs. 1000 per month were associated with anemia.

Among dietary factors, lower consumption of fruits, daily caloric consumption of is $<1000$ kilocalories per day, and less consumption of green leafy vegetable were strongly associated with anemia.

Body mass index $(\mathrm{BMI})<18.5 \mathrm{~kg} / \mathrm{m}^{2}$, presence of pallor, and intestinal parasites were significantly associated with anemia in study participants. Of the 150 participants with clinically apparent anemia, $133(88.7 \%)$ actually had anemia. Of the 32 participants with Ascaris ova in the stool, $27(84.4 \%)$ had anemia. All those with Hookworm, Giardia, and Trichuris infestation were anemic.

To rule out the possible effect of confounding and interaction in univariate analysis, binary logistic regression was used as an analytic tool. Table 4 shows binary logistic regression analysis. Variables found significant in univariate analysis were considered for logistic regression analysis. The dependent variable in the analysis is anemia status. Naglkerke $R^{2}$ statistic and the Hosmer and Lemeshow goodness of fit were used to assess the integrity of the mathematical model used. Model diagnostics are given in Table 5a and b.

Model diagnostics (Cox and Snell $R^{2}$, Nagelkerke $R^{2}$, and Hosmer and Lemeshow test) indicate excellent fit. Thus, the mathematical model used is stable.It is evident from logistic regression analysis that BMI, per capita income, and intestinal parasites in stool were variables that were independently associated with anemia.

\section{DISCUSSION}

The overall prevalence of anemia in adolescent girls was $78.3 \%$. Of the 162 study participants with anemia, 104 (64.2\%) had mild, $59(36.2 \%)$ had moderate, and only 1 participant $(0.6 \%)$ had severe anemia. $65.2 \%$ had hypochromic microcytic anemia and $14.5 \%$ 


\begin{tabular}{|c|c|c|c|}
\hline Variables & Total & $\begin{array}{c}\text { Anemia } \\
\text { present (\%) }\end{array}$ & $P$ \\
\hline \multicolumn{4}{|l|}{ Age (years) } \\
\hline$<13$ & 47 & $42(89.4)$ & 0.088 \\
\hline $13-15$ & 81 & $59(72.8)$ & \\
\hline $16-19$ & 79 & $61(77.2)$ & \\
\hline \multicolumn{4}{|l|}{ Family size } \\
\hline Up to 4 members & 59 & $40(67.8)$ & 0.02 \\
\hline$>4$ members & 148 & $122(82.4)$ & \\
\hline \multicolumn{4}{|l|}{ Mothers education } \\
\hline Illiterate and up to primary & 35 & $28(80.0)$ & 0.264 \\
\hline Primary completed & 122 & $99(81.1)$ & \\
\hline $\begin{array}{l}\text { Secondary and higher secondary } \\
\text { completed }\end{array}$ & 50 & $35(70.0)$ & \\
\hline \multicolumn{4}{|l|}{ Mothers occupation } \\
\hline Housewife & 191 & $154(80.6)$ & 0.004 \\
\hline Private & 16 & $8(50)$ & \\
\hline \multicolumn{4}{|l|}{ Per capita income (Rupees per month) } \\
\hline$<1000$ & 93 & $82(88.2)$ & 0.0001 \\
\hline$\geq 1000$ & 114 & $80(70.2)$ & \\
\hline \multicolumn{4}{|l|}{ Variables related to diet } \\
\hline \multicolumn{4}{|l|}{ Fruits consumption per week } \\
\hline$\leq 1$ & 70 & $64(91.5)$ & $<0.0001$ \\
\hline$>1$ & 137 & $98(71.6)$ & \\
\hline \multicolumn{4}{|l|}{$\begin{array}{l}\text { Daily caloric consumption } \\
\text { (Kilo calories per day) }\end{array}$} \\
\hline $1000-1500$ & 92 & $76(82.6)$ & 0.092 \\
\hline $1501-2000$ & 104 & $80(76.9)$ & \\
\hline$>2000$ & 11 & $6(54.5)$ & \\
\hline \multicolumn{4}{|l|}{$\begin{array}{l}\text { Frequency of green leafy vegetables } \\
\text { per week }\end{array}$} \\
\hline$\leq 1$ & 44 & $40(90.9)$ & 0.021 \\
\hline More than 1 & 163 & $122(74.8)$ & \\
\hline \multicolumn{4}{|l|}{$\begin{array}{l}\text { Anthropometric and clinical findings } \\
\text { BMI }\left(\mathrm{kg} / \mathrm{m}^{2}\right)\end{array}$} \\
\hline$<18.5$ & 130 & $115(88.5)$ & 0.0001 \\
\hline$\geq 18.5$ & 77 & $47(61.0)$ & \\
\hline \multicolumn{4}{|l|}{ Clinically apparent pallor\# } \\
\hline Present & 150 & $133(88.7)$ & 0.0001 \\
\hline Absent & 57 & $29(50.9)$ & \\
\hline \multicolumn{4}{|l|}{ Stool examination } \\
\hline \multicolumn{4}{|l|}{ Intestinal parasites } \\
\hline Present & 65 & $60(92.3)$ & 0.00092 \\
\hline Absent & 142 & $102(71.8)$ & \\
\hline \multicolumn{4}{|l|}{ Type of intestinal parasite $\$$} \\
\hline No intestinal parasite & 134 & $96(71.6)$ & 0.005 \\
\hline Ascaris & 32 & $27(84.4)$ & \\
\hline Hookworm & 12 & $12(100.0)$ & \\
\hline Giardia & 10 & $10(100.0)$ & \\
\hline Entamoeba histolytica & 17 & $15(88.2)$ & \\
\hline Trichuris & 2 & $2(100.0)$ & \\
\hline Total & 207 & $162(78.3)$ & \\
\hline
\end{tabular}

participants had dimorphic anemia. After logistic regression analysis, it was found that BMI, per capita income, and intestinal parasites in the stool were the factors independently associated with anemia.
The prevalence $(78.3 \%)$ of anemia of our study was within the range of prevalence reported by ICMR multicenter study, that is, ranging from $58.2 \%$ to $100 \% .{ }^{\left[{ }^{[]}\right.}$Verma et al. ${ }^{[10]}$ reported prevalence of anemic among adolesenct girls as $81.8 \%$.

However, the prevalence of anemia was $98.1 \%$ for urban areas of Thane district of Maharashtra as reported by Reproductive and Child Health Survey 2002-2003, ${ }^{[11]}$ which is much higher than what is being found in our study.

Mehta, ${ }^{[8]}$ Rajaratnam et al., ${ }^{[12]}$ and Vasanthi et al. ${ }^{[13]}$ have reported prevalence of $64 \%, 48.8 \%$ and $25 \%$, respectively. These prevalences were less than the prevalence of our study. These variations in prevalence are because of difference in the geographical areas of study and minor differences in the age groups.

A study conducted by Chaturvedi et al. ${ }^{[14]}$ (1996) revealed that $93.4 \%$ of study participants had BMI $<18.5 \mathrm{~kg} / \mathrm{m}^{2}$. Kaur et al. ${ }^{[15]}$ had reported that $60 \%$ of study participants were aware of anemia as a health problem and sources of iron-rich foods. In our study, only $6.8 \%$ participants were aware of sources. Thus, there was definite difference in the knowledge of anemia and awareness regarding sources of iron-rich foods.

As per study of Verma et al., the most common blood picture was hypochromic microcytic $(55.5 \%)$. The prevalence of dimorphic anemia was only $1.7 \% .^{[10]}$ In our study, the prevalence of hypochromic microcytic anemia and dimorphic anemia was $60.8 \%$ and $12.3 \%$, respectively.

This indicates that one of the causes of high prevalence of anemia among participants in our study was deficiency of iron and folic acid in their diet.

Another cause of anemia in our study was high prevalence (31.4\%) of the intestinal parasite in the stool. Mahajan et al. ${ }^{[16]}$ reported that the prevalence of intestinal parasites was $21.5 \%$ and this is lower $(31.4 \%)$ than what we found in our study.

As reported by World Health Organization, ${ }^{[17]}$ chronic fecal blood loss due to hookworm infection is a significant contributor to anemia (particularly moderate and severe anemia) among certain populations. In the present study, one of the participants who had severe anemia also had hookworm infection. This indicates worm infestation is still the important cause of severe anemia.

In this study, a kappa value of 0.404 and 0.403 indicated moderate agreement $(P<0.0001$, very highly significant). It is clear that clinical examination of conjunctiva and nail bed can be a very good indicator of anemia. This finding is similar to a study conducted by Chandrasekhar et al. ${ }^{[18]}$ who reported that the most common clinical presentation of study participants with anemia was paleness of eyes.

A study was conducted by Kapur et al. who reported that the sensitivity and specificity of clinical screening for anemia using 


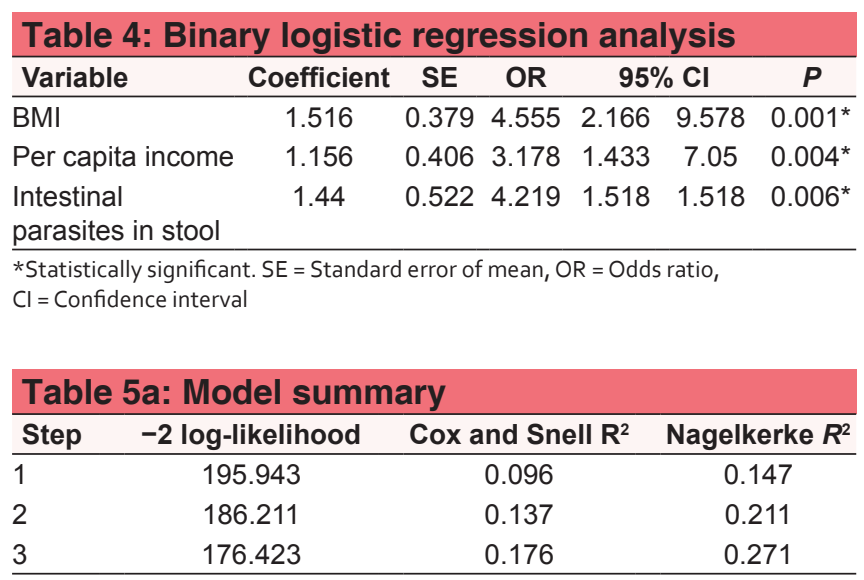

\begin{tabular}{lccc}
\multicolumn{4}{l}{ Table 5b: Hosmer and Lemeshow test } \\
\hline Step & $\boldsymbol{X}^{2}$ & Degree of freedom & Significance \\
\hline 1 & 0.00 & 0 & 0.0 \\
2 & 4.158 & 2 & 0.125 \\
3 & 8.190 & 6 & 0.225 \\
\hline
\end{tabular}

conjunctival pallor was $49 \%$ and $79 \%$, respectively, for identifying children who were severely anemic $(<7 \mathrm{gm} / \mathrm{dl}) \cdot{ }^{[19]}$

Banerjee et al. reported that the average caloric intake among adolescent girls was $1438 \mathrm{kcal} /$ day that is lower than the mean caloric intake of $1542.15 \mathrm{kcal} /$ day, of 10-12 years age group study participants of our study. ${ }^{[20]}$

The Ministry of Health and Family Welfare, Government of India, has launched the Weekly Iron and Folic Acid Supplementation Program to reduce the prevalence and severity of nutritional anemia in adolescent population (10-19 years). Under this program, IFA tablet and albendazole tablets for de-worming are being administered twice a year to the same target groups. ${ }^{[21]}$

This study had limitations, as Sahli's method was used for estimation of hemoglobin, which is not a gold standard method; however, this is a most common method that is still being used in public health facilities for estimation of hemoglobin and hence it was used in this study.

\section{CONCLUSIONS}

High prevalence of anemia among adolescent girls indicates the need for additional nutritional support of iron and folic acid supplementation and prevention and control of worm infestation in urban communities. The knowledge regarding anemia and iron-rich food is low. Thus, specific Information Education and Communication to improve their knowledge on anemia in community can also contribute toward reducing the prevalence of anemia. It would be desirable that action for improvement is initiated right at the adolescent stage, thereby ensuring adequate body stores of iron even before they marry and become pregnant.

\section{Acknowledgment}

We thank all interns and undergraduate students of Grant Medical Collect who were part of this study. We thank Dr. M. K. Kakeri, Professor, GMC Mumbai, for providing guidance. We would like to thank Dr. Manohar Kamble and Dr. Ruchi Jain, the two postgraduate students who were actively involved in data collection for this study. We would extend thanks to all the study participants and their parents for allowing their children to participate in this study.

\section{Financial support and sponsorship}

Nil.

\section{Conflicts of interest}

There are no conflicts of interest.

\section{REFERENCES}

1. Ministry of Home Affairs, Government of India. Profile of Adolescents and Youth in India: Gender Composition of Adolescent and Youth Population Office of the Registrar General \& Census Commissioner, India. Available from: http://www.countryoffice.unfpa.org/india/drive/2-A\&YProfile_ GenderComposition.pdf. [Last accessed on 2015 May 15].

2. www.nrhm.gov.in: National Rural Health Mission. Background note on Adolescent Health. Available from: http://www.nrhm.gov.in/nrhmcomponents/rmnch-a/adolescent-health/2014-02-25-09-42-57/ background-rksk.html. [Last accessed on 2015 May 15].

3. Institute of Health Management Pachod. The transition from Adolescence to Womanhood-policy implications. Pune: IHMP; 1999. p. 1-16.

4. Rajammal $P$ Devadas. Nutritional challenges India faces today. Indian J Nutr Diet 1993;30:217-79.

5. Government of India. Adolescent Health Division. Ministry of Health and Family Welfare, New Delhi, January 2014. Rashtriya Kishor Swasthya Karyakram, Operational Frame Work; 2014.

6. UN Millenium Project: Goals, Targets and Indicators. Available from: http://www.unmillenniumproject.org/goals/gti.htm. [Last accessed on 2015 May 15].

7. World Health Organisation. Sample Size Determination. Geneva: World Health Organisation; 1993. p. 25.

8. Mehta MN. UNICEF, Effectiveness of daily \& weekly IFA supplementation in anemic adolescent girls. Mumbai: Bombay Urban ICDS Project; 1998. p. 21-5.

9. Indian Council of Medical Research. Multicentre Study "District Nutrition Project." New Delhi: Indian Council of Medical Research; 2001. p. 1-10.

10. Verma A, Rawal VS, Kedia G, Kumar D, Chauhan J. Factors influencing anaemia among girls of school going age (6-18 years) from the slums of Ahmedabad city Indian J Community Med 2004;29:125-6.

11. Reproductive and Child Health Survey II, District Thane, Maharashtra; 2002-03.

12. Rajaratnam J, Abel R, Asokan JS, Jonathan P. Prevalence of anemia among adolescent girls of rural Tamil Nadu. Indian Pediatr 2000;37:532-6.

13. Vasanthi G, Pawashe AB, Susie H, Sujatha T, Raman L. Iron nutritional status of adolescent girls from rural area and urban slum. Indian Pediatr 1994;31:127-32.

14. Chaturvedi S, Kapil U, Gnanasekaran N, Sachdev HP, Pandey RM, Bhanti T. Nutrient intake amongst adolescent girls belonging to poor socioeconomic group of rural area of Rajasthan. Indian Pediatr 1996;33:197-201.

15. Kaur M, Singh K. Effect of health education on knowledge, attitude and practices about anaemia among rural women in Chandigarh. Indian J Community Med 2001;26:128-32.

16. Mahajan M, Mathur M, Talwar V, Revathi G. Prevalence of intestinal parasitic infections in East Delhi. Indian J Community Med 1993;18:177-9.

17. WHO. Hookworm infection and anaemia. Approaches to prevention and control. Geneva: WHO; 1991. p. 9-15. 
18. Chandrasekhar U, Radhadev S, Latha R. Prevalence of anaemia in selected rural and urban areas of Coimbatore. Indian J Nutr Diet 1993;30:29-36.

19. Kapur D, Agarwal KN, Sharma S. Detecting iron deficiency anemia among children (9-36 months of age) by implementing a screening program in an urban slum. Indian Pediatr 2002;39:671-6.
20. Banerjee S, Mahindra SK, Bandyopadhyay A. The food intake of adolescent college girls of Rajasthan. Indian $\mathrm{J}$ Med Res 1963;51:494-501.

21. Government of India. RCH-Division-Ministry of Health and Family Welfare, June 2012. Operational Framework Weekly Iron and Folic Acid Supplementation Programme for Adolescents; 2012. 